\title{
RECOVERY AND RECRYSTALLIZATION AFTER CRITICAL STRAIN IN THE NICKEL-BASED SUPERALLOY RENÉ 88DT
}

\author{
D.D. Whitis \\ GE Aircraft Engines, 1 Neumann Way, Evendale, OH 45215 USA
}

Keywords: superalloys, René88DT, grain growth, Critical Grain Growth, CGG, Abnormal Grain Growth, AGG

\begin{abstract}
Critical Grain Growth (CGG) in powder metallurgy nickelbased superalloys is defined as abnormally coarse grains growing in a region of critical strain or strain rate after heat treatment above the gamma prime solvus temperature. As these large grains can be detrimental to the fatigue life of an aircraft engine component, a better understanding of the mechanism of this phenomenon is desired. An initial Double Cone (DC) study was performed to examine the effect of initial grain size on the critical strain, and a more focused Right Circular Cylinder (RCC) study was conducted to identify the nature of recrystallization above, at, and below the critical strain. TEM, SEM, X-Ray Diffractometry, and optical microscopy were used to document the dislocation structure, crystallographic grain structure, and secondary phases in the microstructure. It was found that recrystallization, not recovery, occurs above, at, and below the critical strain for CGG after supersolvus heat treatment, and is complete before CGG begins. This result is at odds with current theory that explains CGG as either a recrystallization phenomenon, or driven by dislocation structure in boundaries after recovery. However, this work confirms the theory that recovery occurs for subsolvus temperatures, which has proven to be a method to reduce the severity of CGG. These two results show that recrystallization is required for CGG to occur. Alternative mechanisms for CGG are discussed.
\end{abstract}

\section{Background}

Critical Grain Growth (CGG) In Nickel-Based Superalloys

The nickel-based superalloy René 88 DT (Defect Tolerant) is of particular interest for aircraft engine turbine disk applications due to its high temperature strength and resistance to fatigue crack growth [1]. Upon heat treatment of René 88 DT (R88DT) forgings above the gamma prime $\left(\gamma^{\prime}\right)$ solvus temperature, an abnormally large grain size evolves in locations which have undergone a critical strain rate at elevated temperature, or experienced a critical amount of strain at room temperature [24]. Since the abnormally large grains which form may be undesirable in service, a better understanding of the recrystallization and recovery behavior prior to CGG is desired in order to shed light on the driving force for grain growth and its correlation with strain. Other nickel-based superalloy systems have shown this strain-related grain growth phenomenon to occur, such as cast and wrought Waspaloy, Inconel X-550, and Nimonic 80A [5], as well as powder metallurgy alloys N18 [6], René 95 [7], and Astroloy [8]. A "Double-Cone" (DC) specimen (Figure 1) with a fixed strain gradient has been used at General Electric Aircraft Engines Division (GEAE), Evendale, OH, [1] to examine a range of strains or strain rates in one specimen. The specimens were hot compressed at various strain rates and temperatures, heated above the $\gamma^{\prime}$ solvus, sectioned, polished, and etched for optical grain size evaluation. In specimens that underwent $\mathrm{CGG}$, the regions of large grains were correlated to a particular strain rate range via comparison to a Finite Element Model (FEM) strain rate contour map. However, despite an extensive database produced and analysis of the CGG response to different chemistry and processing variables, a mechanistic theory could not be developed which explained all of the observed results.

The critical strain and strain rate are presumably related by the resultant dislocation structure that they produce. During hot forging, a slower strain rate encourages superplasticity, characterized by grain boundary sliding and minimal dislocation generation; a faster strain rate requires dislocation generation to accommodate the imposed strain. Since the dramatic grain growth initiates in a small window of strain or strain rate, the phenomenon is called either Critical Grain Growth (CGG) or Secondary Recrystallization (SRX). To use the terminology "recrystallization" implies that the driving force is driven by a difference in dislocation density between a strain-free nucleus and the strained matrix grains, which seems logical enough when the grain growth phenomenon appears to be occurring at a critical strain. However, attempts to prove that the CGG/SRX was a strain-driven process have so far been thwarted by experiment, as detailed below.

Initial Theories Of CGG: CSA And AGG

Observations of CGG were initially attributed to Critical Strain Annealing (CSA) [4], the recrystallization phenomenon in which the critical amount of strain provides the dislocation density required to form recrystallization nuclei in the material, either by Particle Stimulated Nucleation (PSN) $[9,10]$ or by Strain Induced Boundary Migration (SIBM) [11]. The driving force for grain growth would therefore be the difference in free energy between the dislocation-free nuclei and the dislocation-rich surrounding grains. Benson [12] developed a recrystallizationbased model, based on work by Wert and Austin [13], which accurately reproduced the growth behavior associated with CGG. However, TEM work by Benson [12] to confirm this theory showed that the dislocation structure in R88DT is either recovered or recrystallized at temperatures below the $\gamma^{\prime}$ solvus $\left(1107^{\circ} \mathrm{C}\right)$, before any abrupt coarsening of the grain size. The TEM results suggested that the CGG process was not a recrystallization phenomenon, since the dislocation substructure appeared to be annealed out before the CGG event.

If dislocation structure is not the driving force for grain growth in CGG, we must examine other possibilities. Normal grain growth arises from the driving pressure on a grain boundary due to the curvature imposed on a three-dimensional grain boundary 
array [14]. Abnormal Grain Growth (AGG) can occur when normal grain growth is inhibited in some manner, and the variation in this inhibition allows selected grains to have a growth advantage over its neighbors and grow faster than the average grain size. In bulk materials, this inhibition can occur from 1) Particle Pinning (Zener Pinning) [15], 2) Texture Inhibition [16], 3) Solute Drag [17], and in thin films or near free surfaces, 4) Thermal Grooving [18] can occur. Any of these sources of grain boundary inhibition can, in theory, lead to AGG. Both statistical [19] and deterministic [20-21] models have been used to model various abnormal grain growth phenomenon.

Particle Pinning Humphreys [22] has derived stability bounds for a given grain size, its boundary mobility, and its boundary energy relative to the average, outside which the grain structure is unstable and will initiate AGG. However, transient, finitedifference formulations of a Hillert-like formulation, using an initial log-normal grain size distribution and particle pinning only, do not produce an AGG event unless the initial grain size distribution is significantly perturbed, such as adding a grain which is $10-100 \mathrm{X}$ the average grain size [12, 23-24]. This has also been the result of multiple MC analyses [25-27]. While unrecrystallized powder particles approach this size (-270 mesh $\leq 53 \mu \mathrm{m})$, these particles are found randomly in a billet; they do not correlate to the critically strained region that undergoes CGG.

Texture Inhibition Unlike AGG from particle pinning, the case of AGG occurring from a difference in grain boundary energy (i.e. crystallographic texture) has been reproduced in Monte Carlo (MC) simulations $[25,28]$, with growth similar to that found experimentally in rolled $\mathrm{Al}$ [29] and $\mathrm{Cu}$ [30]. In those cases, "secondary recrystallization" occurs from the strong cube $\{001\}<100>$ texture produced after primary recrystallization. Similarly, recrystallization phenomenon can be modeled by Humphreys [31] as an AGG phenomenon using the instabilities created in a sub-grain array with an orientation gradient.

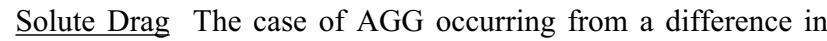
grain boundary mobility has been reproduced in MC simulations $[25,28]$. Although AGG from solute drag is not generally discussed in the literature, there are some industrially important AGG processes which have defied explanation, as they produce a strong texture after AGG; namely, the case of AGG of $\{110\}<001>$ Goss grains in $3 \% \mathrm{Si}$-Fe transformer steels $[32,33]$. It is still a subject of much debate as to how the strong texture evolves, but may be related to the mobility of Coincident Site Lattice (CSL) $\Sigma 5$ boundaries in the primary recrystallized structure [34-38].

None of the above AGG theories depend explicitly on prior strain; they would require that the prior critical strain caused a local variation in the inhibiting force.

\section{Variables Which Affect CGG}

The carbon content [5], the use of a sub-solvus anneal prior to the supersolvus heat treatment $[5,39]$, and the initial grain size [40] have been found to affect the critical strain level in CGG.

Carbon Content Carbon content [5] has been shown to affect the critical strain/strain rate required to initiate CGG. As the carbon content was increased, the critical amount of room temperature strain increased [5]. While the particle size distribution or volume fraction of carbides was not determined, it was assumed that a larger volume fraction of carbides would be present due to the increased amount of carbon. Presumably, the larger volume fraction would provide a larger pinning force against any kind of boundary migration after the dissolution of the $\gamma^{\prime}$, whatever the driving force for CGG might be.

Subsolvus Anneal If a critically deformed superalloy is annealed at a temperature $100^{\circ} \mathrm{C}$ below the $\gamma^{\prime}$ solvus before subjecting it to the standard supersolvus anneal, then the required amount of strain or strain rate for CGG is increased, and the size of the abnormal grains is reduced [5, 39]. It is difficult to say how a subsolvus anneal could increase any inhibiting force against grain growth. At subsolvus temperatures, the carbide/borides require many hours to coarsen, as shown in Table 1, and coarsening of the carbides/borides would only decrease the pinning pressure from the particles. However, the subsolvus anneal could decrease the dislocation density such that a higher strain is required to initiate recrystallization. How recrystallization is related to CGG was still not clear.

Table 1. Particle coarsening kinetics at $1050^{\circ} \mathrm{C}$ [12].

\begin{tabular}{|c|c|}
\hline $\begin{array}{c}\text { Time at } \mathbf{1 0 5 0}^{\circ} \mathbf{C}, \\
\text { hrs }\end{array}$ & $\begin{array}{c}\text { Particle } \\
\text { Diameter, } \boldsymbol{\mu m}\end{array}$ \\
\hline 0 & 0.12 \\
\hline 8 & 0.17 \\
\hline 168 & 0.29 \\
\hline
\end{tabular}

Initial Grain Size Cho and Yoon [40] have supersolvus heat treated specimens of as-extruded R88DT before roomtemperature compression, producing an initial grain size of $14 \mu \mathrm{m}$ compared to the as-extruded $1-5 \mu \mathrm{m}$. After various amounts of room temperature deformation and a second heat treatment for one hour at $1150^{\circ} \mathrm{C}$, the larger initial grain size produced two critical strain regimes; instead of 4-6\% [2], large grains appeared in specimens with $2 \%$ and $10 \%$ room temperature strain. It was expected that, if $\mathrm{CGG}$ is related to the prior amount of strain, the critical strain should increase for the larger grain size; the dislocation density for a fixed amount of strain should be less for the larger grained material due to HallPetch considerations [17]. In the work by Cho and Yoon, the idea was put forth that Extrinsic Grain Boundary Dislocations (EGBD) were driving the growth of the CGG grains at the low strains, and that in the case of $\mathrm{CGG}$ from an as-extruded microstructure, a non-equilibrium, faceted grain boundary structure created during the recovery of dislocations into the grain boundaries.

The current experimental evidence for the driving force of CGG in R88DT is contradictory. While carbon does affect the CGG response of the material, it is hard to understand how such a small prior strain could affect the local carbide distribution. Although subsovus annealing also affects CGG, TEM studies to date do not show evidence of dislocation structure in the grains during the CGG process. The present work was undertaken in order to understand the dislocation structure evolution during annealing, before CGG begins, such that driving force for CGG may be determined. 


\section{Experimental Procedure}

An initial Double Cone (DC) study was conducted to examine the effect of grain size on the critical strain for CGG, while a more focused Right Circular Cylinder (RCC) deformation study was performed to identify the nature of recrystallization above, at, and below the critical strain. Material for the two studies was supplied by GE Global Research Center, Niskayuna, NY, in the form of an as-extruded slice (\#4490) of commercial Powder Metallurgy (PM) R88DT. The composition of this extrusion may be found in the work of Benson, who used the same material in his studies [12].

Two Double Cone (DC) specimens shown in Figure 1 and thirty Right Circular Cylinder (RCC) compression specimens (14.2 $\mathrm{mm}$ in height $7.37 \mathrm{~mm}$ in diameter) were machined from the extrusion slice, with the cylindrical axis parallel to the extrusion axis.

One of the DC specimens and all of the RCC specimens were left in the as-extruded (AE) condition, while the other DC specimen was supersolvus heat treated (HT) at $1150^{\circ} \mathrm{C}$ for 1 hour in a vacuum furnace partially backfilled with argon to produce a larger initial grain size. Both DC specimens were then compressed at room temperature to $13 \%$ reduction in height using a 300 kip Baldwin hydraulic press in the Concrete Lab of the Virginia Transportation Research Council (VTEC), at a crosshead speed of $0.01 \mathrm{in} / \mathrm{min}$. The RCC specimens were compressed to achieve $3 \%, 6 \%$, and $10 \%$ plastic equivalent strain in the center of the specimen using an MTS 810 hydraulic Materials Test System with a 20 kip load cell and a crosshead speed of $0.02 \mathrm{inch} / \mathrm{min}$. Compression platens were made from M2 tool steel, and Teflon tape was used to reduce friction and prevent barreling of the samples. The corresponding plastic equivalent strain (PEEQ) contours were calculated for both the DC and RCC specimens using ABAQUS FEM software, using axisymmetric CAX4R elements to model the DC specimen and an experimental stress-strain curve for room temperature compression of as extruded R88DT conducted at GE Global Research Center.

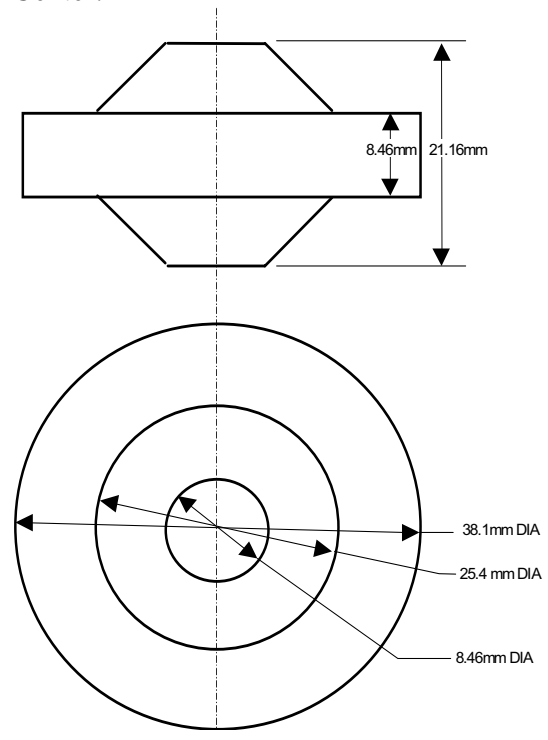

Figure 1. Double Cone (DC) strain gradient sample dimensions.
Double Cone (DC) Study

Figure 2 shows a schematic of the thermo-mechanical processing route for the two DC specimens. The specimens were sectioned into 16 identical pie-shaped sections using a water-cooled Buehler Isomet Plus precision abrasive saw with an Acu-Thin $\mathrm{SiC}$ blade. Individual sections were then subjected to interrupted heat treatments. From each DC specimen, six sections were individually placed in a Nichrome wire cage, preheated for $3 \mathrm{~min}$ at $900^{\circ} \mathrm{C}$, and then submerged in a barium chloride $\left(\mathrm{BaCl}_{2}\right)$ salt bath maintained at $1150^{\circ} \mathrm{C}$ using a type $\mathrm{K}$ thermocouple and kept under a blanket of argon. The salt bath consisted of a round-bottomed mullite tube resting on refractory brick spacers inside the hot zone of a vertical Linberg Blue tube furnace. Heat treatment times were 10, 30, 60, 90, 120, and 180 seconds. In all cases, the sections were water quenched after heat treatment to prevent cooling $\gamma^{\prime}$ from forming, although fine $\gamma^{\prime}$ precipitation $(10-20 \mathrm{~nm})$ could not be suppressed. An optical mount was produced from each section; the details of preparation may be found in [41]. Grain sizes were taken via the Heyne intercept method using ASTM E112-88 from optical or TEM microphotographs.

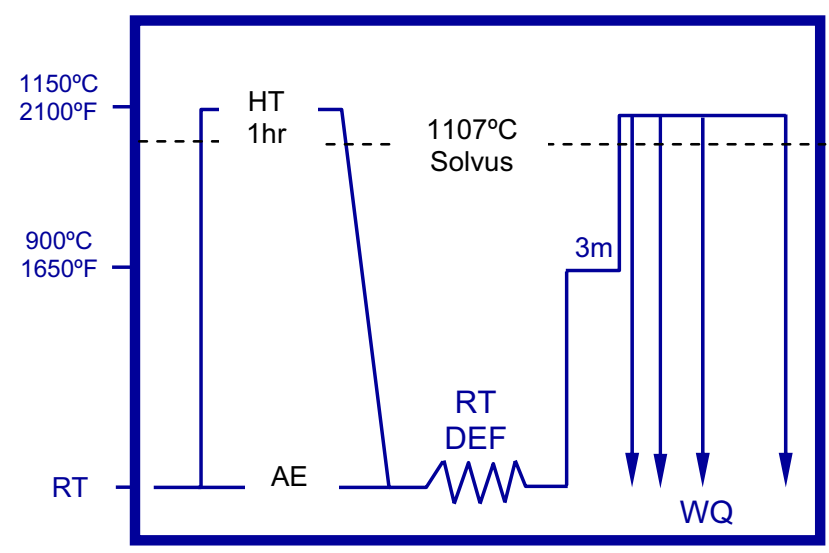

Figure 2. Schematic of Thermo-mechanical processing route for $\mathrm{AE}$ and HT DC specimens.

Right Circular Cylinder (RCC) Study

After compression to $3 \%, 6 \%$, or $10 \%$ plastic equivalent strain, the RCC specimens were longitudinally sectioned with a lowspeed diamond saw, creating two $2 \mathrm{~mm}$ thick slices down the center. Additionally, a $1 \mathrm{~mm}$ diameter hole was drilled in the top corner of each slice. Each slice was suspended by a Nichrome wire and submerged in the barium chloride $\left(\mathrm{BaCl}_{2}\right)$ salt bath previously described for times indicated in Table 2 . For the RCC study, the salt bath temperature was continuously monitored using type $\mathrm{R} \mathrm{Pt}-13 \% \mathrm{RhPt}$ thermocouple enclosed in mullite. Argon was bubbled continuously through the bath using a mullite tube to produce an argon atmosphere during heat treatment and avoid oxidation of the sample. A graphite rod was descended into the bath for 20 minutes prior to heat treatment to remove trace oxygen and metal contaminants. Two slices from each of the compression specimens were heat treated at the same conditions to provide one sample for optical/SEM evaluation and one sample for TEM evaluation. Additional longer time heat treatments were added to the $1050^{\circ} \mathrm{C}$ testing due to the slower recrystallization kinetics at that temperature. 
Table 2. Heat treatments conducted for RCC Study.

\begin{tabular}{|c|c|c|}
\hline Strain & $\mathbf{1 0 5 0}^{\circ} \mathbf{C}$ & $\mathbf{1 1 5 0}^{\mathbf{}} \mathbf{C}$ \\
\hline $\mathbf{3 \%}$ & $10,30,60 \mathrm{~s}, 2 \mathrm{~m}, 15 \mathrm{~m}$ & $10,30,60 \mathrm{~s}$ \\
\hline $\mathbf{6 \%}$ & - & $10,30,60 \mathrm{~s}$ \\
\hline $\mathbf{1 0} \%$ & $10,30,60 \mathrm{~s}, 2 \mathrm{~m}$ & $10,30,60 \mathrm{~s}$ \\
\hline
\end{tabular}

One heat treated slice was used for Optical and Scanning Electron Microscopy. Optical microscopy was performed to document grain sizes, as described for the DC study. However, the grain boundaries of the samples heat treated for 10 seconds at $1150^{\circ} \mathrm{C}$ and all of the $1050^{\circ} \mathrm{C}$ samples were still pinned by primary gamma prime, such that the grain size was too fine for optical resolution. In the TEM, grain size discernment was difficult due to the dislocation density present for these samples. Field Emission Gun (FEG) Scanning Electron Microscopy (SEM) images give the best estimate for grain size in that situation, providing electron channeling contrast due to crystallography. Volume fraction and size of primary and cooling $\gamma^{\prime}$ were determined by etching with a solution of 3 parts glycerol, 3 parts $\mathrm{HCl}, 1$ part $\mathrm{HNO} 3$, and 1 part $\mathrm{HF}$ [42] and using a Zeiss DSM 982 FEG-SEM. This technique allowed primary $(\sim 1 \mu \mathrm{m})$ and larger cooling $(\sim 0.1 \mu \mathrm{m})$ particles to be evaluated, but very fine $(<50 \mathrm{~nm})$ gamma prime was not evaluated in this study, as it would not be present at the temperatures of interest. Volume fractions and $95 \%$ confidence intervals were determined using ASTM E562-89, using 36 fields of 49 points, or 1764 points total for each specimen at $2-5 \mathrm{KX}$. Size distributions were determined by measuring an average diameter from two perpendicular measurements of 40-100 particles.

The other heat treated slice was used for conventional Transmission Electron Microscopy (TEM). Conventional TEM imaging was performed on thin foil specimens on a JEOL 2000 $\mathrm{LaB}_{6}$ microscope operating at $200 \mathrm{kV}$. Dislocation structures and grain boundaries were documented using bright-field images and corresponding diffraction patterns. Recrystallized volume fractions were determined by taking six randomly positioned micrographs at $15 \mathrm{KX}$, sampling approximately 15 grains in each image, or approximately 90 grains total, for each condition, with a field of 460 points per image. Misorientations across specific boundaries were found by first determining the crystallographic orientation of each grain, calculating the misorientation matrix between the two grains, and finally determining an angle/axis representation for the misorientation via individual Kikuchi patterns (taken at $30 \mathrm{~cm}$ ) with the program KIKUCHI, written by Wert [43], based on the work of Thomas and co-workers [44]. Six different measurements of the same Kikuchi pattern yielded the average error of this measurement to be 0.26 degrees.

The crystallographic texture of the RCC samples was obtained using a Scintag X series Automated Diffractometer using $\mathrm{Cu} \mathrm{K}_{\alpha}$ radiation. The samples were examined in the polished and etched (Kallings \#2) condition to assure that any deformation layer was removed. DMSNT software was used for goniometer control and raw data collection. All scans used a $4 \mathrm{~mm}$ oscillation in the long direction of the sample. The raw data files were then analyzed using the Preferred Orientation Package - Los Alamos (popLA) software. Textural strength values (square root of the mean square value of the normalized OD) were calculated with the WIMV (Williams-Imhof-MatthiesVinel) [45] algorithm.

\section{Initial Characterization}

\section{Results}

The grain sizes of the two initial conditions As-Extruded (AE) and Heat Treated (HT) are grain size $0.7 \mu \mathrm{m}$ and $14 \mu \mathrm{m}$ respectively. In the as-extruded condition, we have $35-40 \% \gamma^{\prime}$, where half is primary $\gamma^{\prime}(1 \mu \mathrm{m})$, half cooling, or secondary $\gamma^{\prime}$ $(0.1 \mu \mathrm{m})$, and residual fine tertiary $\gamma^{\prime}(20 \mathrm{~nm})$ form. In the heat treated condition, the primary $\gamma^{\prime}$ is absent; all the $\gamma^{\prime}$ is cooling, or secondary $(0.1 \mu \mathrm{m})$. Also present is a very small volume fraction $(<1 \%)$ of $\mathrm{MC}(\mathrm{M}=\mathrm{Ti}, \mathrm{Nb})$ carbides $(0.1 \mu \mathrm{m})$ and $\mathrm{M}_{3} \mathrm{~B}_{2}$ $(\mathrm{M}=\mathrm{Cr}$, Mo, W) borides, found both at the prior particle boundaries (PPBs) and randomly distributed in the matrix, as well as $\mathrm{ZrO}_{2}$ oxides $(0.1 \mu \mathrm{m})$ that form on the PPBs during powder formation. The PPBs are elongated in the direction of extrusion.

Double Cone Study Results

The optical mounts of the deformed DC specimens after heat treatment at $1150^{\circ} \mathrm{C}$ are shown in Figure 3. The CGG band of large grains appears in the AE sections between 60-90 seconds along the $6-7 \%$ strain contours. Figure $4 \mathrm{a}$ shows the 120 seconds specimen with the FEM plastic equivalent strain contours of $1-10 \%$ overlaid to confirm this. At longer times, these large grains grow preferentially in the low strain direction.

In the HT sections, a band of fine $(6 \mu \mathrm{m})$ grains appears at strains greater than $15 \%$ after 10 seconds at $1150^{\circ} \mathrm{C}$. These grains are less than half the size of the initial grain size $(14 \mu \mathrm{m})$; therefore, the structure has clearly recrystallized. At 180 seconds, a band of large grains begins to form along the $15 \%$ strain contour, as shown in Figure $4 \mathrm{~b}$, similar the band at $6 \%$ strain in the $\mathrm{AE}$ sections shown in Figure 4a. The early refinement in grain size observed above a critical strain in the HT condition is strong evidence that recrystallization has occurred in this region.

However, in the HT sections, we see a phenomenon not observed in the AE condition. A gradual coarsening of the grain size in the rest of the section begins between 10-30 seconds, and runs from $15 \%$ strain to approximately $1 \%$ strain with a grain size of $200 \mu \mathrm{m}$ at the lowest strain level. Below $1 \%$ strain, the grain size is still $14 \mu \mathrm{m}$. For longer times, the coarsening proceeds until the low strain region is made up of very coarse $(1000 \mu \mathrm{m})$ grains. This process looks very different microstructurally from that occurring at the "critical" strain. Figure 5 shows the interface between the coarse and fine grains for the CGG versus the "gradual coarsening" case. In the case of the $\mathrm{AE} 180 \mathrm{~s} / 1150^{\circ} \mathrm{C}$ section, the CGG band of large grains has grown only in the low strain direction, and grows competitively, such that only a few initial grains from the CGG band are consuming the fine grains. In the case of "gradual coarsening" in the HT $120 \mathrm{~s} / 1150^{\circ} \mathrm{C}$ section, new large grains are growing out in front of the coarsening boundary. By impinging on each other, they form a coarser grain size. It is suspected that the absence of primary $\gamma^{\prime}$ in the HT condition is the cause for this difference in behavior, and that this is due to recrystallization occurring normally throughout the specimen, such that at high strains, the grain size is refined, and at low strains, it is coarsened. It should be noted that the evolution of 
two distinct regions of large grains in the HT condition is identical to the previous experiments by Cho and Yoon at KAIST [40]. However, with the DC specimen we can further conclude that the band of large grains at the higher strain is the one that correlates with the CGG band in the AE condition, due to the similarity in boundary morphology.
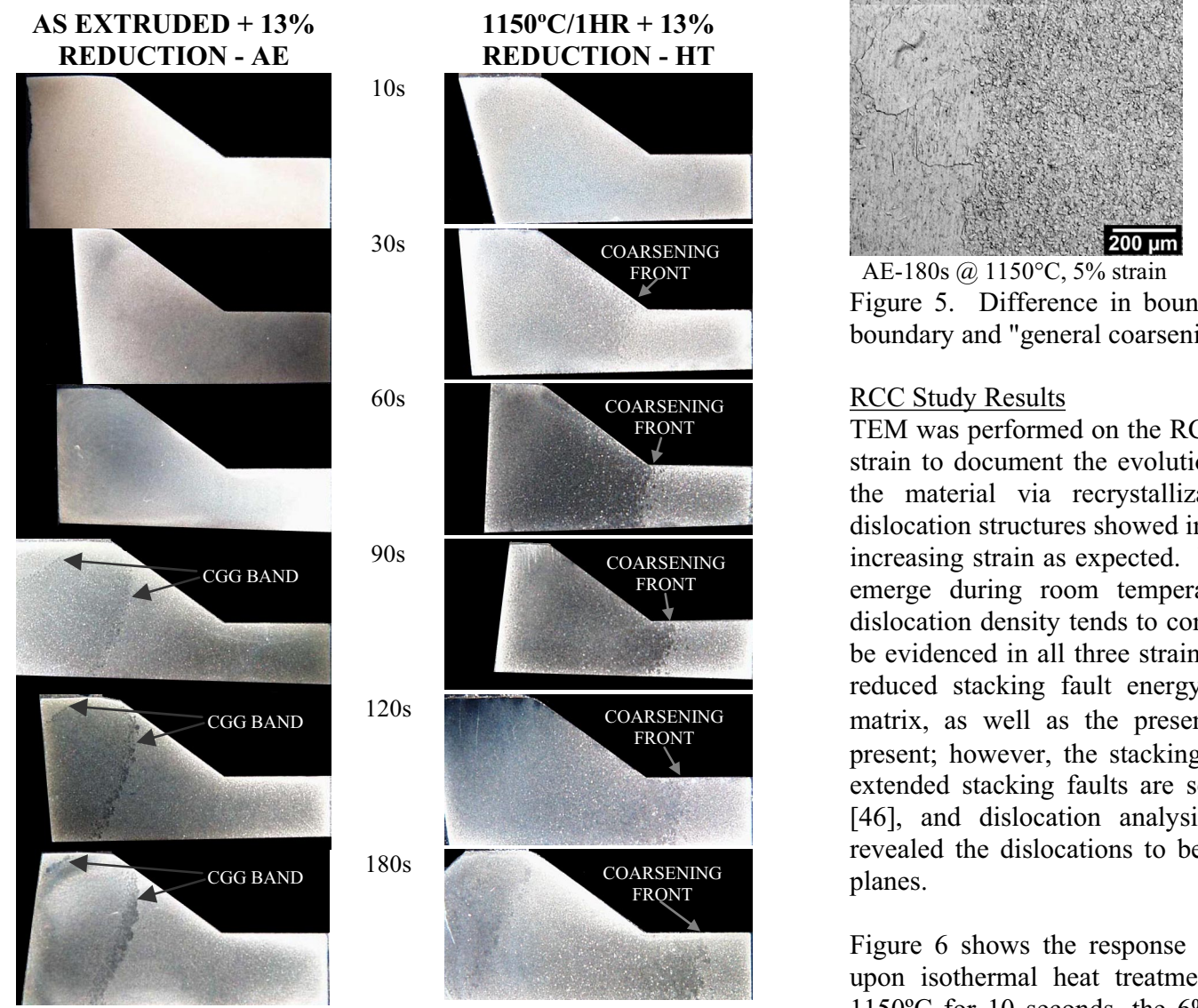

$\mathrm{AE}-180 \mathrm{~s} @ 1150^{\circ} \mathrm{C}, 5 \%$ strain
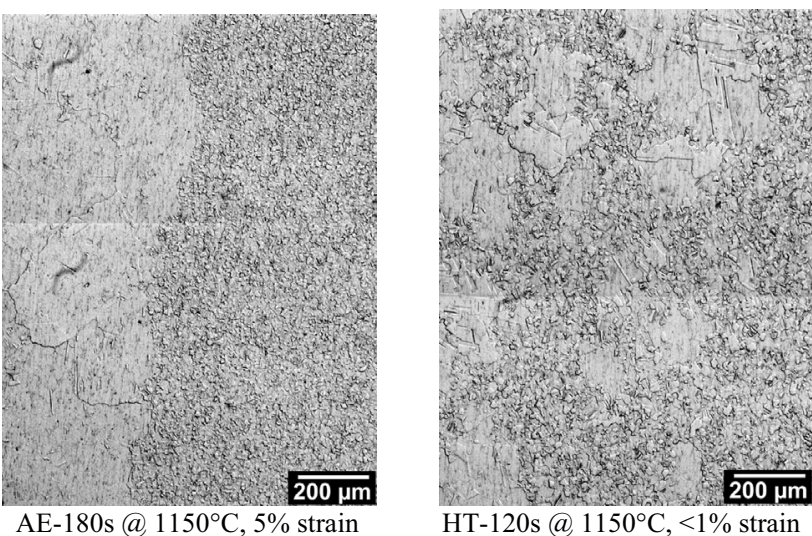

HT-120s@ $1150^{\circ} \mathrm{C},<1 \%$ strain

Figure 5. Difference in boundary morphology between CGG boundary and "general coarsening" boundary in HT condition.

\section{RCC Study Results}

TEM was performed on the RCC specimens with 3,6 , and $10 \%$ strain to document the evolution of the dislocation structure in the material via recrystallization or recovery. The initial dislocation structures showed increasing dislocation density with increasing strain as expected. No cellular dislocation structures emerge during room temperature compression; instead, the dislocation density tends to concentrate on $\{111\}$ planes, as can be evidenced in all three strain levels. This is likely due to the reduced stacking fault energy of the Ni-Cr-Co-X superalloy matrix, as well as the presence of the ordered $\gamma^{\prime}$ particles present; however, the stacking fault energy is not so low that extended stacking faults are seen in the deformation structure [46], and dislocation analysis using 5 difference g-vectors revealed the dislocations to be $1 / 2<110>$ dislocations on $\{111\}$ planes.

Figure 6 shows the response of the deformed microstructures upon isothermal heat treatment at $1050^{\circ} \mathrm{C}$ and $1150^{\circ} \mathrm{C}$. At $1150^{\circ} \mathrm{C}$ for 10 seconds, the $6 \%$ and $10 \%$ strained samples are almost completely recrystallized, except for the stacking faults in the $\gamma^{\prime}$, as shown in Figure 7. This difference in recrystallization behavior between the $\gamma^{\prime}$ particles and the matrix has been previously observed [47]. The 3\% strained sample has only a few recrystallized grains at 10 seconds. Complete recrystallization of the $\gamma$ matrix at $1150^{\circ} \mathrm{C}$ for all three strain conditions is achieved after 30 seconds - both above, equal to, and below the $6 \%$ critical strain.
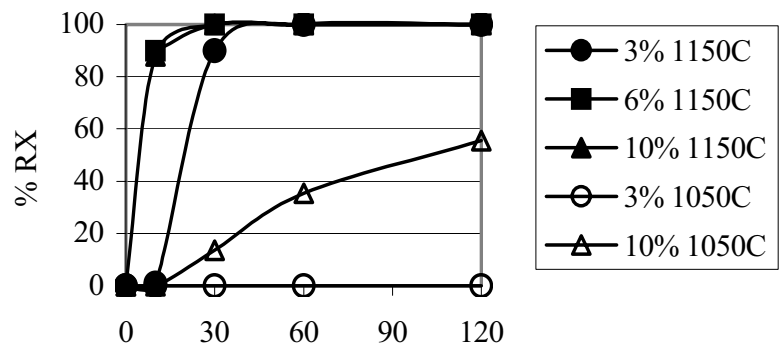

Time, seconds

Figure 6. Plot of the recrystallization kinetics for R88DT deformed at room temperature to $3 \%, 6 \%$, and $10 \%$ strain and heat treated at 1050 or $1150^{\circ} \mathrm{C}$. 
Several $\Sigma 3$ twin boundaries in the $1150^{\circ} \mathrm{C}$ recrystallized specimens were examined in double two-beam conditions, revealing that the twin boundaries in the grains showed no secondary dislocation structure, as shown in Figure 8. The misorientation from the twin orientation was calculated to be $0.06^{\circ}$. This would suggest that recovery to these boundaries did not occur, but that they formed during recrystallization as annealing twins. Also, low angle boundaries could not be found generally in the microstructure as in high stacking fault energy materials such as aluminum. This evidence indicates that, as for other lower stacking fault alloys such as stainless steel, recrystallization has occurred at $1150^{\circ} \mathrm{C}$ before significant recovery could occur.

When heat treated at $1050^{\circ} \mathrm{C}$, however, recrystallization occurs slowly for the $10 \%$ strained sample, and recrystallization does not occur for the $3 \%$ strained sample, even after 60 seconds at $1050^{\circ} \mathrm{C}$. Figure 9 shows that 15 minutes at $1050^{\circ} \mathrm{C}$ is necessary before the 3\% sample shows signs of the dislocation structure evolving, in which case it appears to be annealing into twin and grain boundaries. In the case of the $\Sigma 9$ boundary examined, it is found to be misoriented by $0.85^{\circ}$, with intrinsic grain boundary dislocations visible due to the misorientation, and extrinsic grain boundary dislocations, most likely being absorbed, trailing into the grain.

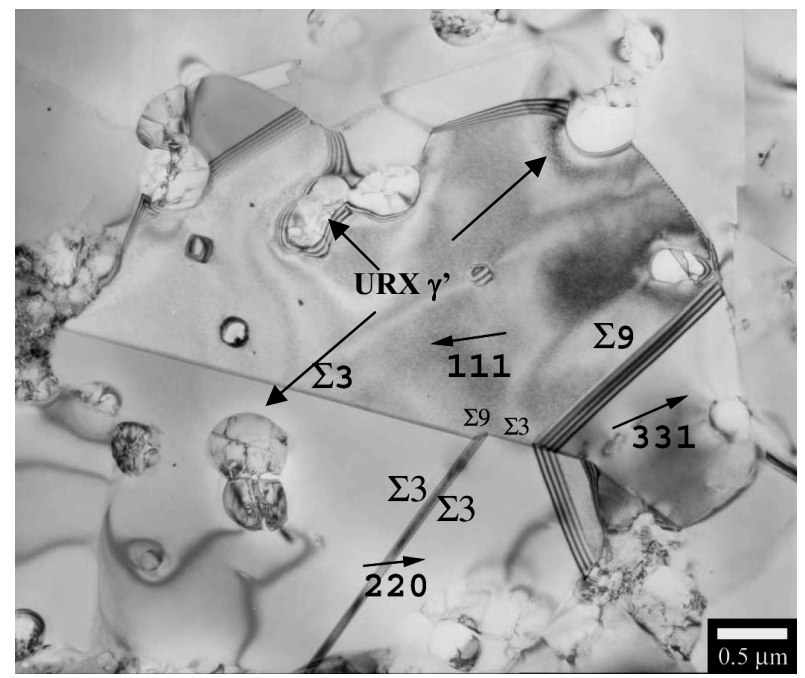

Figure 7. TEM for $6 \%$ strained samples heat treated at $1150^{\circ} \mathrm{C}$ for 10 seconds. Unrecrystallized (URX) $\gamma^{\prime}$ particles in recrystallized $\gamma$ matrix.

\section{Grain Size}

Grain sizes from SEM and optical microscopy are shown in Table 3, Table 4, and Figure 10. For the specimens heat treated at $1150^{\circ} \mathrm{C}$, the grain size grows from the as-extruded 0.7 microns to around 20 microns for the $3 \%$ and $10 \%$, while the $6 \%$ sample becomes bimodal after 60 seconds, with the larger grains at 150 microns. Of interest to note is that the smaller grains of the bimodal grain size at $6 \%$ strain are slightly finer than the average grain size of the $3 \%$ and $10 \%$ samples. For the specimens heat treated at $1050^{\circ} \mathrm{C}$, the grain size grows to around 5 microns after 60 seconds.

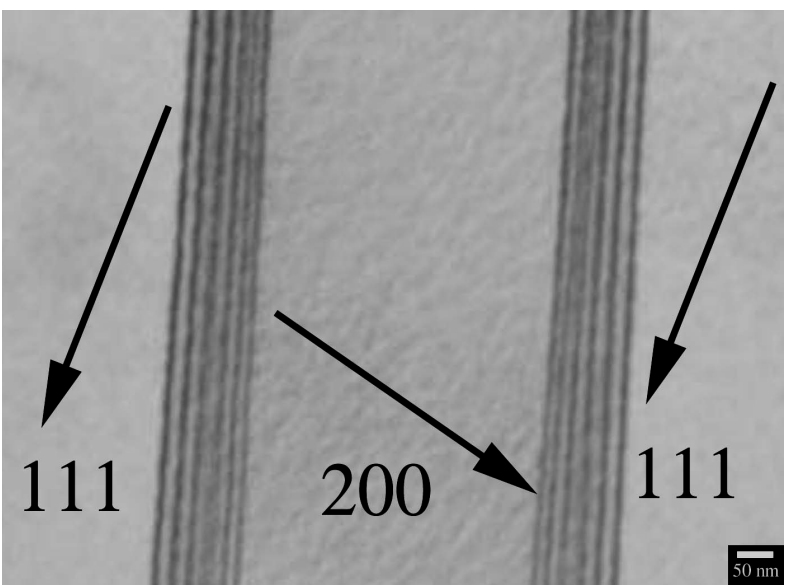

Figure 8. Double two-beam images of two $\Sigma 3$ twin-boundaries in $6 \%$ strain $/ 30 \mathrm{~s} / 1150^{\circ} \mathrm{C}$, where the incident beam is close to $[\overline{1} 4 \overline{3}]$ for $\mathrm{g}=(111)$, and [015] for $\mathrm{g}=(200)$. Measured misorientation from exact $\Sigma 3$ relationship was $0.06^{\circ}$, indicating no significant deviation.

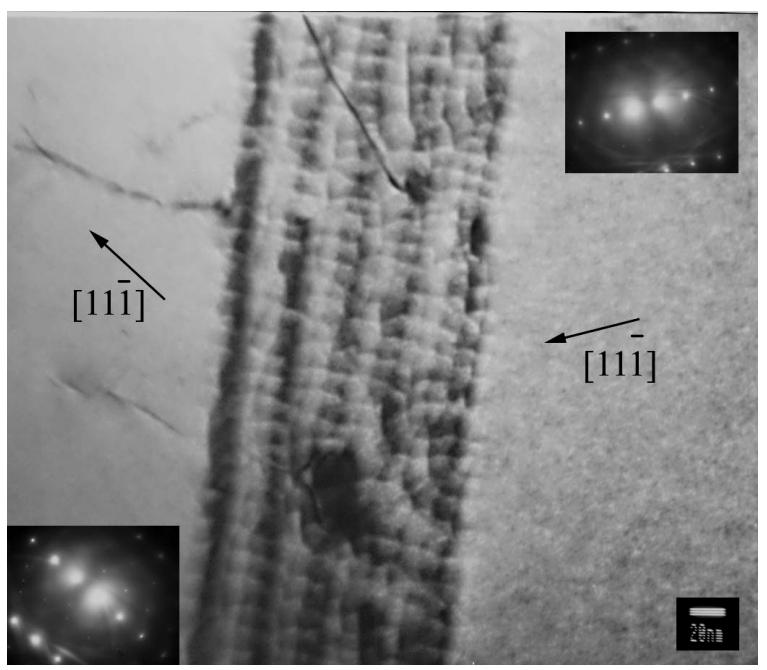

Figure 9. TEM for $3 \%$ strained sample heat treated at $1050^{\circ} \mathrm{C}$ for 15 minutes, showing recovery of dislocations into a near- $\Sigma 9$ boundary and the dislocation network accommodating the slight misorientation from $\Sigma 9$, incident beam is near [321] for both grains. Measured misorientation from exact $\Sigma 9$ relationship was $0.85^{\circ}$.

It should also be noted that the twin boundaries in most samples were not simple linear twins, but complex structures including multiple intersecting twins, as well as twins which deviated from the low-energy $\{111\}$ plane inclination. This type of structure was not only seen at $6 \%$ strain, but for all strains.

The bimodal grain size distribution that evolved is shown in Figure 11. An example of one of the large grains is shown in Figure 12. Although this grain appears to be somewhat elongated in the extrusion direction, in general the large grains grow uniformly in all directions, and are unaffected by the prior particle boundaries (PPBs) in the microstructure. 
Table 3. Grain size for $1150^{\circ} \mathrm{C}$ heat treatments. Duplex bimodal grain size in $6 \% / 60$ seconds sample.

\begin{tabular}{|c|c|c|c|}
\hline $\begin{array}{c}\text { Time at } \\
\mathbf{1 1 5 0}^{\circ} \mathbf{C}(\mathbf{s})\end{array}$ & $\begin{array}{c}\mathbf{3 \%} \\
(\boldsymbol{\mu} \mathbf{m})\end{array}$ & $\begin{array}{c}\mathbf{6 \%} \\
(\boldsymbol{\mu} \mathbf{m})\end{array}$ & $\begin{array}{c}\mathbf{1 0 \%} \\
(\boldsymbol{\mu m})\end{array}$ \\
\hline $\mathbf{1 0 s}$ & 4.0 & 3.5 & 4.3 \\
\hline $\mathbf{3 0 s}$ & 17.7 & 14.3 & 18.1 \\
\hline $\mathbf{6 0 s}$ & 20.1 & $16.2(70 \%)$ & \\
& & $/ 150(30 \%)$ & 18.9 \\
\hline
\end{tabular}

Table 4. Grain size for $1050^{\circ} \mathrm{C}$ heat treatments.

\begin{tabular}{|c|c|c|}
\hline $\begin{array}{c}\text { Time at } \\
\mathbf{1 0 5 0}^{\mathbf{0}} \mathbf{C}(\mathbf{s})\end{array}$ & $\mathbf{3 \%}(\boldsymbol{\mu m})$ & $\mathbf{1 0 \%}(\boldsymbol{\mu m})$ \\
\hline $\mathbf{1 0}$ & 2.8 & 3.3 \\
\hline $\mathbf{3 0}$ & 3.7 & 3.8 \\
\hline $\mathbf{6 0}$ & 4.9 & 5.1 \\
\hline
\end{tabular}

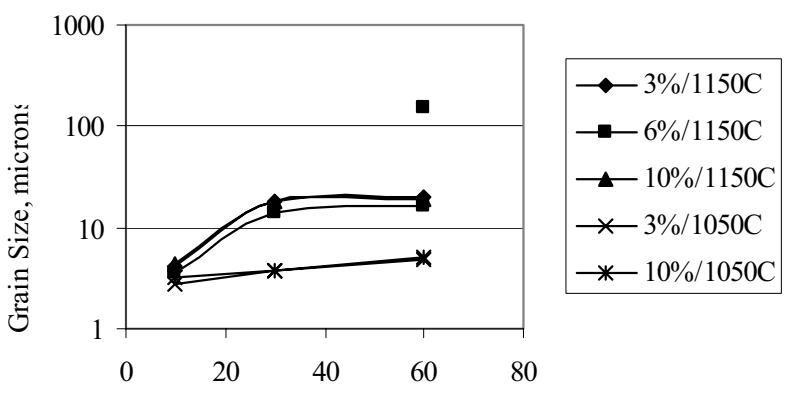

Time, seconds

Figure 10. Grain size as a function of time and strain, at $1150^{\circ} \mathrm{C}, 1050^{\circ} \mathrm{C}$.

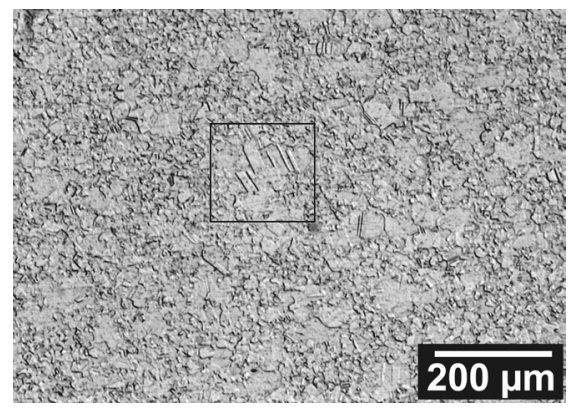

Figure 11. Optical micrograph showing bimodal grain size in $6 \%$ critical strain sample, heat treated at $1150^{\circ} \mathrm{C}$ for 60 seconds, Kallings \#2 etch. Boxed region in Figure 12.

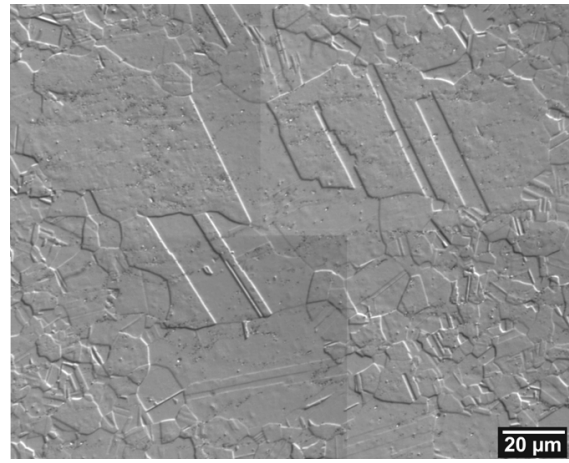

Figure 12. Larger magnification of area in box in Figure 16. Abnormal grain grows to consume smaller grains around it, Kallings \#2 etch.
Gamma prime size and volume fraction

As it was observed that CGG did not occur until the $\gamma^{\prime}$ had gone into solution, it was of interest to characterize the $\gamma^{\prime}$ volume fraction in this study, and document the grain size that should occur due to its pinning effect. The $\gamma^{\prime}$ volume fraction decreases with time at temperature, with no significant difference between strain levels, as plotted in Figure 13. At $1150^{\circ} \mathrm{C}$, most of the cooling $\gamma^{\prime}$ has dissolved even before 10 seconds, and almost complete dissolution of the primary $\gamma^{\prime}$ has occurred by 60 seconds. At $1050^{\circ} \mathrm{C}$, there is still $15 \%$ volume fraction $\gamma^{\prime}$ even after 60 seconds, which still retains a bimodal character of initial primary and cooling $\gamma^{\prime}$.

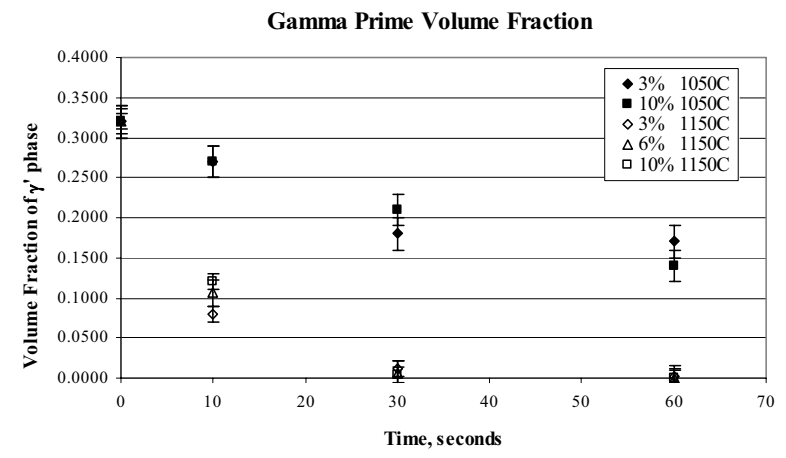

Figure 13. Evolution of $\gamma^{\prime}$ volume fraction with time and temperature.

\section{X-ray Diffractometry}

Texture measurements were performed to examine the likelihood that a strong initial texture is responsible for CGG. Figure 14 shows Inverse Pole Figures (IPFs) in the extrusion direction for the specimens heat treated at $1150^{\circ} \mathrm{C}$. The asextruded sample shows a $\langle 111>$ fiber texture, which is commonly found in fcc metals after extrusion [48]. This $<111>$ fiber texture remains after heating the material without any deformation, for 30 minutes at $1108^{\circ} \mathrm{C}$ (approximately the solvus temperature). The textural strength of both of these textures was found to be 1.03 , where a random texture has a strength of 1 , and a highly textured, rolled sheet could have a texture near 4 [49]. This indicates that the texture is very weak, and would not lead to a grain boundary structure prone to AGG solely through grain boundary energy considerations.

The as-deformed $3 \%, 6 \%$, and $10 \%$ specimens show a progressive weakening of the $<111>$ fiber texture, and strengthening of the $\langle 110\rangle$ fiber texture, which has also been shown to occur in fec metals both experimentally and via Taylor-type simulations taking the initial $<111>$ texture as input [48]. Upon heat treatment, these as-deformed textures change to a "recrystallized texture", showing an absence of the prior $<111>$ or $<110>$ texture, and the appearance of a slight $<212>$ and $<203>$ texture, but with textural strengths of 1.01-1.02, even weaker than the original as-extruded texture. For the $6 \%$ and $10 \%$ strained samples, the change in texture occurs before 10 seconds at $1150^{\circ} \mathrm{C}$, whereas the $3 \%$ sample still retains the $<111>$ texture at 10 seconds, and converts to the new texture between 10 seconds and 30 seconds. This result corresponds exactly with the TEM results, which indicated that 
recrystallization occurred before 10 seconds for both the $6 \%$ and $10 \%$ samples, while recrystallization occurred between 10 seconds and 30 seconds for the 3\% sample. Finally, we should note that there was no change in the texture of the $6 \%$ sample heat treated at $1150^{\circ} \mathrm{C}$ for 60 seconds as compared to earlier times, despite the fact that CGG has occurred.
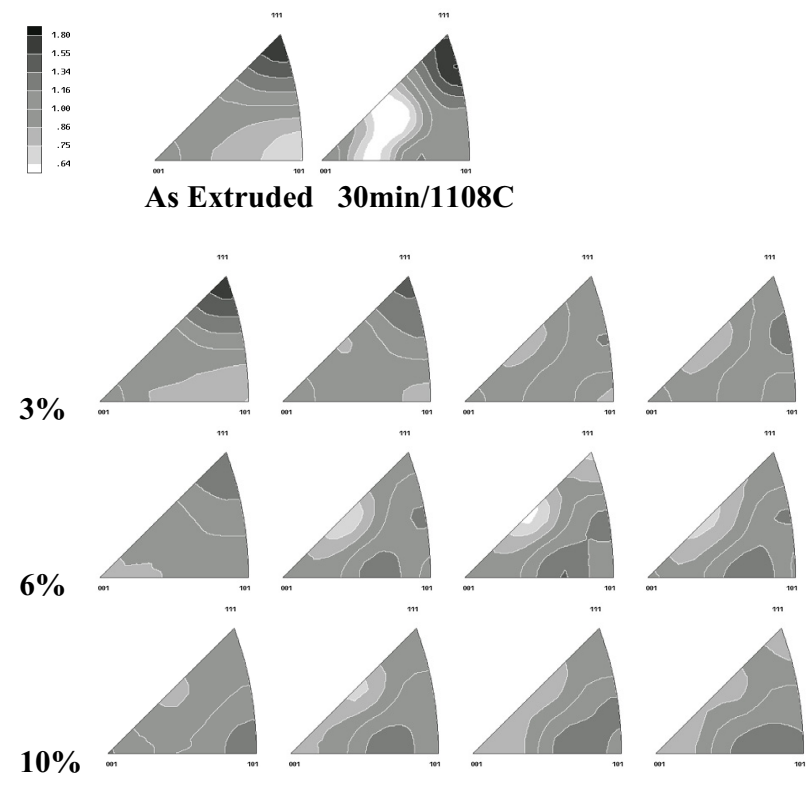

AS DEF $\quad 1^{10 s} / 1150^{\circ} \mathrm{C} \quad 30 \mathrm{~s} / 1150^{\circ} \mathrm{C} \quad 60 \mathrm{~s} / 1150^{\circ} \mathrm{C}$

Figure 14. IPFs for R88DT, as-extruded, as-deformed and after heat treatment at $1150^{\circ} \mathrm{C}$.

\section{Discussion}

The difference in grain size in the initial DC study has definitely produced a difference in CGG response. In the AE condition, the critical strain is $6-7 \%$, and in the HT condition it occurs at $\sim 15 \%$ strain. This should be expected, as a larger grain size material will tend to have a lower dislocation density for the same amount of strain [17]. The coarsening grain size at lower strains in the HT case from 30-180 seconds appears to be due to a wave of "normal" recrystallization, not a separate CGG event at low strain, as was proposed by Cho and Yoon [40]. As mentioned previously, this is likely due to the absence of primary $\gamma^{6}$ in the HT condition.

Both the TEM evidence and the X-Ray Texture measurements in the RCC study support the conclusion that recrystallization has occurred at all three strains $(3 \%, 6 \%$, and $10 \%)$ at $1150^{\circ} \mathrm{C}$ before $30 \mathrm{~s}$. No recovered structures were observed below the critical strain, and no twin boundaries were especially populated by either extrinsic or intrinsic boundary dislocations. A difference in recovery versus recrystallization is observed at $1050^{\circ} \mathrm{C}$; after two minutes at that temperature, there is $50 \%$ recrystallization at $10 \%$ strain, but only recovery processes occur for the sample strained to $3 \%$. Here, the heat treatment (subsolvus anneal) which is generally purported to decrease the likelihood or severity of CGG in fact shows a difference in dislocation evolution above and below the critical strain. From these results we must conclude that dislocation substructure, either in the grains or on grain boundaries, cannot be the driving force for the CGG event.
Comparing the size and volume fraction of $\gamma^{\prime}$ particles with the grain size for the $3 \% / 1150^{\circ} \mathrm{C}$ samples, we see that the grain size predicted by the Zener equation [15] is in good agreement with the measured grain size at 10 and 30 seconds. However, at 60 seconds, the predicted grain size is six times larger that the measured grain size.

Table 5. Comparison of calculated pinned grain size with actual grains size for $3 \%$ strain $/ 1150^{\circ} \mathrm{C}$.

\begin{tabular}{|c|c|c|c|c|}
\hline $\begin{array}{c}\text { Time, } \\
\text { seconds }\end{array}$ & $\begin{array}{c}\text { Average } \\
\text { particle } \\
\text { diameter, } \\
\mathbf{d}, \boldsymbol{\mu m}\end{array}$ & $\begin{array}{c}\text { Volume } \\
\text { fraction } \\
\boldsymbol{\gamma}, \mathbf{f}\end{array}$ & $\begin{array}{c}\text { Calculated } \\
\text { Zener } \\
\text { pinned } \\
\text { grain size, } \\
\mathbf{2 d} / \mathbf{3 f}, \boldsymbol{\mu m}\end{array}$ & $\begin{array}{c}\text { Measured } \\
\text { grain size, } \\
\boldsymbol{\mu m}\end{array}$ \\
\hline $\mathbf{1 0}$ & 0.412 & 0.080 & 3.43 & 4.0 \\
\hline $\mathbf{3 0}$ & 0.381 & 0.012 & 21.17 & 17.7 \\
\hline $\mathbf{6 0}$ & 0.360 & 0.002 & 120 & 20.1 \\
\hline
\end{tabular}

In fact, this calculated grain size at 60 seconds is comparable to the size of the large grains growing in the $6 \%$ strain sample. It therefore appears that the specimens which do not exhibit CGG are not really so "normal" in their grain growth behavior. These grains are presumably pinned by the carbides, borides, and oxides in the matrix still present at that temperature. Benson [12] calculated the total volume fraction of these particles to be 0.00712 , with an average diameter of 0.1 microns, which would produce a limiting grain size of 9.4 microns. As it was unclear as to how recrystallization could affect these particles, a systematic study of their chemistry, size and spatial distribution was not attempted in this work. However, a future study in this area of may provide more insight into the operative CGG mechanism.

A more recent theory of CCG put forth by Yoon and co-workers [50] is one in which grain growth stagnates when faceted grain boundaries meet general boundaries at triple junctions. While in the present RCC TEM study, facetted boundaries were observed as shown in Figure 15, the facets were not on general boundaries as Yoon suggests, but only on twin or twin variants. If the faceting of the boundaries is inhibiting normal grain growth, it is possible that the twinning events during recrystallization are the missing link between dislocation structure and grain boundary stability.

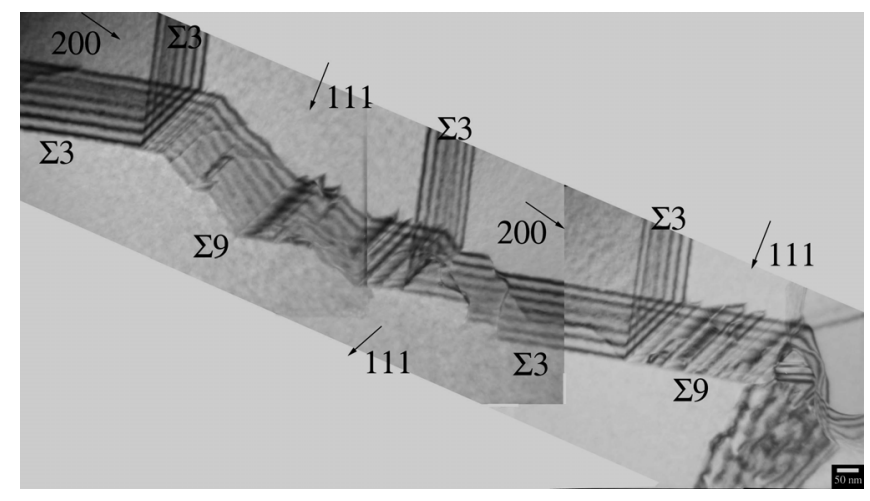

Figure 15. Double two-beam condition, showing faceting along twin-variant boundaries in R88DT, where the incident beam is close to [-14-3] for $\mathrm{g}=111$, and [015] for $\mathrm{g}=200$. 


\section{Conclusions}

The examination of the evolving dislocation density, crystallographic texture, and grain boundary structure in room temperature deformed R88DT has shown that CGG in this material is not driven by dislocation structure, nor by texture. Recrystallization occurs at, above, and below the critical strain, leaving no dislocation structure, EGBDs or low angle boundaries in the structure at the time of critical grain growth. What we do find is a structure that is heavily twinned, with a slightly finer grain size in the critically strained region. Recovery of the dislocation structure is confirmed at subsolvus temperatures. Further work on the stability of the carbides and borides in the structure during recrystallization, as well as further characterization of the grain boundary misorientation distributions for the structure will likely be key in further understanding the CGG phenomenon.

\section{Acknowledgements}

This work was sponsored by General Electric Global Research Center in Niskayuna, NY, and performed at the University of Virginia Materials Science and Engineering Department, Charlottesville, VA. Valuable technical consultation was provided by Profs. Gary Shiflet, James Howe and Sean Agnew of the University of Virginia, Dr. John Wert of the RISØ National Laboratory, Prof. Duk Yoon of the Korean Advanced Institute of Science and Technology, Dr. Michael Henry and Paul Follensbee of GE Global Research Center, and Mr. Eric Huron of GE Aircraft Engines.

1. D.D. Krueger, R.D. Kissinger, and R.G. Menzies. Development and introduction of a damage tolerant high temperature nickel-base disk alloy, Rene88DT, in Superalloys 1992, TMS (1992) 277.

2. Huron, E.S., S. Srivatsa, and E. Raymond. Control of grain size limits via forging strain rate limits in R88DT. in Superalloys 2000. TMS (2000) .

3. Blankenship, C.P., et al., Recrystallization and grain growth in strain gradient samples. Scripta Metallurgica et Materialia, 1994. 31(6): p. 647.

4. Blankenship, C.P., et al., Hot-Die Forging of P/M Ni-Base Superalloys, in Superalloys 1996, R.D. Kissinger, et al., Editor. 1996, The Minerals, Metals \& Materials Society. p. 653.

5. Decker, R.F., et al., Abnormal Grain Growth in Nickelbase Heat-resistant alloys, in Technical Note 4082. 1957, National Advisory Committee for Aeronautics: Washington DC. p. 1.

6. Soucail, M., M. Marty, and H. Octor, The effect of high temperature deformation on grain growth in a P/M nickel base superalloy, in Superalloys 1996, R.D. Kissinger, et al., Editor. 1996, The Minerals, Metals \& Materials Society. p. 663.

7. Menon, M.N. and F.J. Gurney, Microstructural Investigation of the Growth of Large Grains in Prealloyed Powder Extrustions of a Nickel Base Superalloy. Metallurgical Transactions, 1976. 7A: p. 731.

8. Dahlén, M. and L. Winberg, Grain coarsening of PM nickel-base superalloy by critical strain annealing. Metal Science, 1979. april: p. 163.
9. Humphreys, F.J., Nucleation of Recrystallization in metals and alloys with large particles, in Proceedings of the 1st Riso International Symposium on Metallurgy and Material Science, N. Hansen, et al., Editor. 1980, Risø National Laboratory: Roskilde, Denmark. p. 35.

10. Nes, E., Recrystallization in alloys with bimodal particle size distributions, in Proceedings of the 1st Riso International Symposium on Metallurgy and Material Science, N. Hansen, et al., Editor. 1980, Risø National Laboratory: Roskilde, Denmark. p. 85.

11. Beck, P.A. and P.R. Sperry, Strain Induced Grain Boundary Migration in High Purity Aluminum. Journal of Applied Physics, 1950. 21(2): p. 150.

12. Benson, W.E., A Model to Describe the Effect of Initial Grain Size Distribution on Abnormal Grain Growth with Application to Rene 88DT, (Ph.D. thesis, University of Virginia, 1998).

13. Wert, J.A. and L.K. Austin, Modeling of Thermomechanical Processing of Heat-Treatable Aluminum alloys. Metallurgical Transactions A, 1988. 19: p. 617.

14. Burke, J.E. and D. Turnbull, Recrystallization and Grain Growth. Progress in Metal Physics, 1952. 3: p. 220.

15. Smith, C.S., Grains, Phases, and Interfaces: An Interpretation of Microstructure. Transactions of the AIME, 1948. 175: p. 15.

16. Read, W.T. and W. Schockley, Dislocation models of crystal grain boundaries. Physical Review, 1950. 78(3): p. 275.

17. Humphreys, F.J. and M. Hatherly, Recrystallization and Related Annealing Phenomena. 1996, Oxford: Elsevier Science Ltd.

18. Hazzledine, P.M. and C.H. Wörner, An analytical model for secondary recrystallization, in Modeling of Coarsening and Grain Growth, P.C.S.a.M. S.P., Editor. 1993, The Minerals, Metals \& Materials Society.

19. Atkinson, H.V., Theories of normal grain growth in pure single phase systems. Acta Metallurgica, 1988. 36(3): p. 469.

20. Anderson, M.P., et al., Computer Simulation of Grain Growth -- I. Kinetics. Acta Metallurgica, 1984. 32(5): p. 783.

21. Humphreys, F.J., A network model for recovery and recrystallization. Scripta metallurgica et materialia, 1992. 27: p. 1557.

22. Humphreys, F.J., A unified theory of recovery, recrystallization and grain growth, based on the stability and growth of cellular microstructures- II. The effect of second-phase particles. Acta Materialia, 1997. 45(12): p. 5031.

23. Benson, W.E. and J.A. Wert, The effect of initial grain size distribution on $A G G$ in single-phase materials. Acta Materialia, 1998. 46(15): p. 5323.

24. Benson, W.E. and J.A. Wert, The effect of initial grain size distribution on abnormal grain growth: a model based on Hillert's formulations, in Grain Growth in Polycrystalline Materials III, H. Weiland, Adams, B.L. and Rollett, A.D., Editor. 1998, The Minerals, Metals \& Materials Society. p. 125.

25. Srolovitz, D.J., G.S. Grest, and M.P. Anderson, Computer Simulation of Grain Growth -- V. Abnormal Grain growth. Acta Metallurgica, 1985. 33(12): p. 2233. 
26. Doherty, R.D., et al., Effect of secondary phase particles on grain growth in three dimensions, in Simulation and Theory of Evolving Microstructures, M.P.a.R. Anderson, A.D., Editor. 1990, The Minerals, Metals \& Materials Society. p. 3.

27. Hazzledine, P.M. and R.D.J. Oldershaw, Computer simultation of Zener pinning. Philosophical Magazine A, 1990. 61(4): p. 579.

28. Rollett, A.D., D.J. Srolovitz, and M.P. Anderson, Simulation and theory of abnormal grain growth-anisotropic grain boundary energies and mobilities. Acta Metallurgica, 1989. 37(4): p. 1227.

29. Bowles, J.S. and W. Boas, The effect of crystal arrangement on secondary recrystallization in metals. Journal of the Institute of Metals, 1948. 74: p. 501.

30. Kronberg, M.L. and F.H. Wilson, Secondary Recrystallization in Copper. Metals Transactions, 1949. 185: p. 501.

31. Humphreys, F.J., A unified theory of recovery, recrystallization and grain growth, based on the stability and growth of cellular microstructures- I. The basic model. Acta Materialia, 1997. 45(10): p. 4231.

32. May, J.E. and D. Turnbull, Secondary Recrystallization in Silicon Iron. Transactions of the Metallurgical Society of AIME, 1958. 212: p. 769.

33. Hayakawa, Y., et al., A mechanism of Goss texture development during secondary recrystallization in electrical steel, in Grain Growth in Polycrystalline Materials III: Proceedings of the third international conference on grain growth (ICGG-3), H. Weiland, Adams, B.L. and Rollett, A.D., Editor. 1998, The Minerals, Metals \& Materials Society: Warrendale, PA, USA. p. 615.

34. Harase, J., et al., Effect of primary recrystallization texture, orientation distribution and grain boundary characteristics on the secondary recrystallization behavior of grainoriented silicon steel haing AlN and MnS as inhibitors, in Proceeding from the 4th International Symposium on Grain Boundary Structure and Related Phenomena. 1986, Japan Institute of Metals. p. 563.

35. Gangli, P. and J.A. Szpunar, The use of sigma operators in the investigating secondary recrystallizationof $3 \%$ silicon steel. Materials Science Forum, 1994. 157-162: p. 953.

36. Kurosawa, M., Y. Hayakawa, and M. Komatsubara, Effect of cold reduction on secondary recrystallization stability in grain oriented electrical steel, in Grain Growth in Polycrystalline Materials III, H. Weiland, Adams, B.L. and Rollett, A.D., Editor. 1998, The Minerals, Metals \& Materials Society. p. 627.

37. Ushigami, Y., K. Murakami, and T. Kubota, Analysis of secondary recrystallization in grain oriented silicon steel by synchrotron x-ray topography, in Grain Growth in Polycrystalline Materials III, H. Weiland, Adams, B.L. and Rollett, A.D., Editor. 1998, The Minerals, Metals \& Materials Society. p. 491.

38. Rajmohan, N., J.A. Szpunar, and Y. Hayakawa, $A$ role of fractions of mobile grain boundaries in secondary recrystallization of $\mathrm{Fe}-\mathrm{Si}$ steels. Acta materialia, 1999. 47(10): p. 2999.

39. Yoon, D.Y., et al., . 1994: U.S. Patent No. 5,529,643.

40. Cho, Y.K., Effect of Low Deformation on Grain Growth in Nickel-Base Superalloy Rene 88, . 1999, Korea Advanced Institute of Science and Technology.
41. DeMania, D.A., "Recovery and Recrystallization in R88" (Ph.D. thesis, University of Virginia, 2002).

42. Zhao, J.-C., V. Ravikumar, and A.M. Beltran, Phase precipitation and phase stability in Nimonic 263. Metallurgical and materials transactions A, 2001. 32(6): p. 1271.

43. Gudmundsson, H., D. Brooks, and J.A. Wert, Acta metallurgica et materialia, 1991. 39: p. 19.

44. Okamoto, P.R., E. Levine, and G.J. Thomas, Journal of Applied Physics, 1967. 38: p. 289.

45. Mattheis, S. and G.W. Vinel, On the reproduction of the orientation distribution function of textured samples from reduced pole figures using the concept of conditional ghost correction. Physica Status Solidi B, 1982. 112: p. K111.

46. Kotval, P.S., The microstructure of superalloys. Metallography, 1969. 1: p. 251.

47. Ray, R.K. and B. Bhattacharya. Recrystallization behavior of a Ni3Al (B, Zr) alloy. in Recrystallization and Grain Growth. 2001. Aachen, Germany: Springer-Verlag.

48. Kocks, U.F., C.N. Tome, and H.-R. Wenk, Texture and Anistropy; Preferred Orientations in Polycrystals and their Effect on Materials Properties. 1998, Cambridge: University Press. 676.

49. Prof. Sean Agnew, private communication with author, University of Virginia, March 2002.

50. Lee, S.B., et al., Grain boundary faceting and abnormal grain growth in nickel. Metallurgical and materials transactions A, 2000. 31(march): p. 985. 